Carlos Petit (2016). Historia del derecho mercantil. Madrid, Marcial Pons.

\title{
Historia, Derecho y Comercio. A propósito de la obra Historia del derecho mercantil del profesor Carlos Petit
}

Reseño ahora un texto que estoy seguro dará de qué hablar, que iluminará varios rincones antes desconocidos gracias a las sombras que sobre ellos recaían, que llenará vacíos a la par que descubrirá otros que retarán a nuevas generaciones de iushistoriadores. Me refiero a la magnífica obra «Historia del derecho mercantil» del profesor de la Universidad onubense, Carlos Petit, con una emotiva y brillante presentación del profesor emérito Manuel Olivencia.

Pero quisiera comenzar esta recensión contando una historia detrás de dicha Historia: la fama de iushistoriador mercantil del profesor Petit cruzó, por sobrados méritos, el Atlántico, pero la consecución de sus obras no ha sido fácil ni en América en general, ni en Colombia en especial. Propuse, pues, al profesor Petit, con mucho respeto, que compilase algunas de sus obras de historia del derecho mercantil, en especial aquellas que tuvieran algo que decirle, desde España, al mundo hispanoamericano. Debo confesar, por los motivos que más adelante señalaré, que fue una estrechez de miras de mi parte, algo que el autor seguramente advirtió desde un inicio pero que por su amabilidad no me reclamó. Sin embargo, él aceptó mi sugerencia y, consciente de las falencias de mi propuesta, rompió el molde sugerido, pues no hizo ni una compilación de trabajos ni mucho menos una versión española de temas mercantiles aplicables al caso americano. ¿Qué terminó siendo, pues, la obra?

Dado el estrecho margen permitido para una reseña, deberé hablar de generalidades para responder la anterior pregunta. En primer lugar, el trabajo no fue una compilación, pues no se trató de una sumatoria de escritos -con vida propia- sobre el campo histórico-jurídico-mercantil. Desde el mismo orden de los capítulos, queda patente una estructura delicadamente construida por el autor, estructura que le dice mucho a quien tiene frente a sí todo el conjunto de la obra pero no a quien se acerque solo a algunos capítulos individualmente considerados (de la estructura aludiré más adelante). Además, el profesor Petit reorganizó internamente los escritos, los actualizó bibliográficamente, 
los enriqueció con notas producto de su actividad investigativa posterior a la publicación inicial y logró armonizarlos con los demás capítulos. Se trató, pues, no de una compilación (ni en el sentido del Antiguo Régimen ni mucho menos en el sentido editorial contemporáneo), sino de una reescritura que se suma, hay que decirlo de una vez, a algunos trabajos inéditos (caps. I, VIII, XIV, XV, XVIII) que se articularon al libro sin hacerle estallar por los aires.

En segundo lugar, esta reescritura da lugar a innovaciones importantes tanto para la iushistoria como para el derecho mercantil. ¿Cuáles son? Varias. Pero quisiera centrarme, con la venia del lector, en dos. La primera es que este libro alude a una historia general del derecho mercantil, pues logra construir una memoria del jurista y del derecho, ${ }^{1}$ a lo largo de la cual se articulan con un excelente manejo narrativo: i) el quehacer de los mercaderes, ii) el contenido de las instituciones y de las normas más relevantes del derecho mercantil, iii) la forma de práctica forense de los juristas, y iv) la construcción de la disciplina académica del derecho mercantil con su respectivo acento universitario. Esto es, en todo sentido, un gran logro en la medida que es raro encontrar un texto que intente articular los cuatro elementos anteriores, por lo que supera así, con creces, los trabajos meramente descriptivistas de la normativa pretérita.

La segunda es que plantea una nueva forma de ver la función de la iushistoria: ser memoria del jurista y de lo jurídico, enmarcado en la cultura de su época (un buen punto de interdisciplinariedad para el «taller del historiador»), ${ }^{2}$ por lo que trasciende la forma institucionalista de exponer la historia del derecho, logrando llevar a esta última a territorios propios de una historia cultural. Esto es claro, especialmente, cuando el profesor Petit explica el ius mercatorum en épocas de Antiguo Régimen (parte primera, caps. I, II, III y IV), que no puede ser comprendido, y allí el error de muchas aproximaciones previas, por fuera de la cultura religiosa, la teología moral, las costumbres familiares y las reglas de

1 «[L]a razón mejor que hoy justifica la presencia de la historia jurídica en los estudios universitarios se encuentra en el cultivo y desarrollo de la llamada memoria del jurista, expresión comprometida que entiendo, provisionalmente, como la tradición "disciplinar" del Derecho y de los que socialmente se identifican como sus expertos (...) en este sentido, no sería el Derecho -presente o pasadoel principal objeto de observación, sino todo aquello que, a propósito del Derecho, han podido decir y escribir personas insertas en ciertas instituciones (tribunales, universidades, parlamentos) encargadas de la producción de textos reputados jurídicos: en otros términos habría que averiguar qué hace que tengamos por especializados (escritos, discursos, personas) a los que, cumplidos ciertos requisitos, así se consideran». Petit, (2005, p. 251-252).

2 Aludiendo así a la exitosa metáfora de Curtis (Curtis, 1975) y Petit (1992). 
honor del gremio (verbigracia, caps. I y V). De esta forma, la obra se convierte, además, en un manual de clases de metodología para la iushistoria, no solo la mercantil, en la medida que plantea una forma de trabajo útil en muchos campos: la comprensión de lo jurídico (que va más allá de las normas) a partir de la cultura que le rodea. ${ }^{3}$ Gracias a este proceder metodológico en el taller del iushistoriador es que las fronteras disciplinarias, otrora fuertes, ahora se difuminan, por lo que surge como posibilidad una historia de los matices que es aquella en la que tanto me empeño.

Empero, justo en este punto, hay que indicar que el autor no mantiene, con la misma fuerza narrativa, su propuesta metodológica al momento de aludir al derecho mercantil decimonónico (parte cuarta), donde la estrategia cultural de comprensión de lo jurídico cede ante la necesidad de explicaciones un poco más juridificantes, cosa que el propio profesor Petit (2016) anuncia con las siguientes palabras:
«Advierto al lector de una apreciable diferencia en el tratamiento dispensado al ius mercatorum y al Derecho mercantil. El mejor conocimiento historiográfico del primero hace posible una síntesis que busca, ante todo, la interpretación. En cambio, para los capítulos que forman la cuarta parte de esta obra la insuficiencia de estudios, unida a la riqueza de las fuentes, me ha llevado a privilegiar la narración» (p. 20).

Tal vez hubiera sido mejor recurrir a otras palabras, pues la interpretación al igual que la narración atraviesan todo el texto, por lo que, creo yo, la diferencia entre ambas partes consiste en que la interpretación narrada es más comprensiva en la primera parte y más explicativa en la segunda. ${ }^{4}$

En tercer lugar, es importante tener en cuenta que este libro no fue un texto español para la América hispana, pero sí un puente español de comunicación entre la cultura europea con la americana. Me explico: no es un texto de historia española del derecho, ni uno de historia del derecho español. Si bien el centro, el mojón sembrado, es eminentemente parte de la cultura hispana (que

3 Pues el «Derecho no es un fenómeno aislado, sino un aspecto de una realidad social global» (Latorre, 1985, p. 111). Esta enseñanza metodológica, de acercar la iushistoria a la cultura que rodea lo jurídico, ya es común en las nuevas tendencias de la disciplina. Ver: Villegas del Castillo (2009). Aún así hace falta una mayor difusión de dicha idea metodológica.

4 Aludo a la diferenciación, presente en la hermenéutica, entre comprender y explicar. Ver Wright (1971, p. 17-56). 
en el Antiguo Régimen, por la extensión del imperio, era mundial), el autor deja en claro que el fundamento que rodea y que permite la comprensión de lo jurídico mercantil ha escapado de las fronteras nacionales y se ubica más en un «horizonte europeo» (Petit, 2016, p. 20), como han escapado de ellas las prácticas comerciales en todo momento, aunque tampoco dichas fronteras puedan ignorarse como si nunca hubiesen existido. Ni tanto que queme al santo, ni tanto que no lo ilumine. Por todo ello, recurre el autor a fuentes generales europeas, jurídicas y culturales, para explicar su objeto de estudio, lo que incluso le permite al lector entender, de una vez por todas, que la historia nacional del derecho ha sido fruto de procesos transnacionales. Un buen ejemplo de esto fue la codificación mercantil en la España decimonónica (parte cuarta, caps. XII al XVIII) que tanto influjo tuvo en América (cap. XIV), lo cual no puede comprenderse a menos que se parta del proceso europeo de racionalización del derecho (parte tercera) y de apropiación (o expropiación) de lo jurídico por parte del Estado (parte cuarta). Esto explica, creo yo, que el título de la obra no se hubiese restringido a moldes que no le habrían calzado (como hubiera sucedido si en él se aludiera a lo español), por lo que se intitula, simplemente, Historia del derecho mercantil, sin más.

En cuarto lugar, la estructura del libro deja en claro, a mi modo de ver, la intención del autor: una mirada de largo aliento de la historia del derecho mercantil, a partir de la exhibición del paso complejo del consuetudinario y teológico ius mercatorum (caps. I-IV), al legislado y estatalizado derecho mercantil moderno (caps. XIV-XVIII). Y esta estructura es la que termina por explicar una idea que rondaba en párrafos anteriores: estamos ante una historia general, no solo por escapar al empobrecido enfoque nacionalista e institucionalista, sino también: (a) por la intención de articular, en una nueva conceptualización del objeto memorístico de la iushistoria, la norma, la profesión forense, la actividad académica y el quehacer de los mercaderes; y (b) porque relaciona la cultura con dicha nueva forma de entender lo jurídico, para facilitar una comprensión hermeneuta más acorde con lo que ha sido el comercio y su regulación en el tiempo. Claro está que, como lo dice el propio autor en su «Presentación» (Petit, 2016, p. 19), y que es más que evidente desde la estructura de la obra, no se habla de la totalidad de las instituciones mercantiles. Pero esto no permite decir que la obra deja de ser general: ¿Qué obra puede hacer tal cosa? Como bien dijo el recién fallecido Paolo Prodi: «Tal vez la edad del libro concebido como producto finito y concluso al cual la empastadura imprime el sello definitivo 
de completo y perpetuo, que las recensiones pueden solo alabar o despedazar, está por terminar» (Prodi, 1992, p. 19) ${ }^{5}$. Aun así, a pesar de que no estamos en épocas enciclopédicas y conclusivas en las obras académicas, este sí es un buen texto general porque reúne, con armonía notoria, una buena parte de (la historia del autor que ha sido dedicada a) la historia del derecho mercantil.

En conclusión, esta obra se convierte en un texto de referencia (a) porque no es una mera compilación de textos ya conocidos, sino una reescritura de varios textos previos sumados a otros inéditos, con una nueva mirada sinóptica y general que solo los años y la experiencia del autor pueden ofrecer; (b) porque se convierte en un manual metodológico importante a tener en cuenta en el «taller del historiador» sobre cómo superar los rígidos y los pobres esquemas meramente descriptivos, institucionalistas y nacionalistas, gracias a la consideración de que el derecho al ser historiado (i) va más allá de la norma y (ii) no puede comprenderse por fuera de la cultura que lo rodea, lo que logra una ventaja adicional: el libro sirve, por su amplitud de fuentes y miradas, no solo al iushistoriador, sino también al historiador general y al dogmático comercialista; ${ }^{6}$ y (c) porque se convierte en una obra que expone la esencia mundializada de la circulación de instituciones jurídicas por el Atlántico, entre el Viejo y el Nuevo Mundo (ver cap. XIV), sirviendo así este texto también como obra de referencia en el derecho comparado, porque deja en claro, con mirada de largo aliento, el proceso de transformación del derecho mercantil más allá de un país, lo que evita miradas estáticas de las prácticas jurídicas.

5 Traducción propia del italiano.

6 Lo que permitiría, además, cumplir una función legitimante de la iushistoria al interior de la disciplina científico-jurídica: dialogar con el dogmático: «En ese orden de ideas, concebir la iushistoria como una disciplina jurídica permitiría de mejor manera el cumplimiento de su función o misión memorística, en un diálogo especialmente con el jurista dogmático. Una historiografía del Derecho pensada como historiografía profesional, tal como se ha venido haciendo por algunos, impide el acercamiento del dogmático que desea saber el/su pasado, aquello que fue jurídico o reputado como tal en su propia área del Derecho, pues el discurso disciplinario y la precisión conceptual que requeriría el dogmático del Derecho contemporáneo no la encontrará en el historiador» (Botero, 2010, p. 63). 


\section{Bibliografía}

Botero-Bernal, A. (2010). Presupuestos epistemológicos y metodológicos de la iushistoria. Precedente. Revista Jurídica, 45-70.

Curtis, L. P. (Comp.) (1975). El taller del historiador. Trad. Juan José Utrilla. México, Fondo de Cultura Económica.

Latorre, Á. (1985). Introducción al estudio del Derecho. Barcelona, Ariel.

Petit, C. (1992). Oralidad y escritura, o la agonía del método en el taller del jurista historiador. Historia, instituciones, documentos, (19), 327-379.

Petit, C. (2005). De la historia a la memoria. A propósito de una reciente obra de historia universitaria. Cuadernos del Instituto Antonio de Nebrija de estudios sobre la universidad, (8), 237-280.

Petit, C. (2016). Historia del derecho mercantil. Madrid, Marcial Pons.

Prodi, P. (1992). Il sacramento del potere: il giuramento politico nella storia costituzionale dell'Occidente. Bologna, Il Mulino.

Villegas Del Castillo, C. (2009). Historia y Derecho: La interdisciplinariedad del Derecho y los retos de la Historia del Derecho. Revista de Derecho Público, 22, 2-22.

Wright, G. H. V. (1971). Explicación y comprensión, trad. Luis Vega Reñón. Madrid, Alianza Universidad.

Andrés Botero

Profesor de la Universidad Industrial de Santader. Presidente de la Asociación Colombiana de Filosofía del Derecho y Filosofía Social (Asofides). Presidente del Instituto Colombiano de Historia del Derecho. 